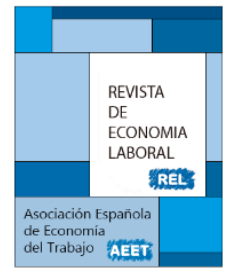

\title{
LAS REFORMAS LABORALES APROBADAS DURANTE LA CRISIS ECONÓMICA: UNA PERSPECTIVA ECONÓMICA
}

\author{
José Ignacio Pérez Infante \\ Economista
}

Recibido Julio 2015; Aceptado Octubre 2015

\section{Resumen}

El artículo tiene como objetivo principal servir de marco al número monográfico dedicado al análisis desde una perspectiva económica de las reformas laborales aprobadas desde el inicio de la crisis económica. En el artículo se analizan los aspectos comunes a estas reformas, destacando la prioridad de todas ellas al objetivo de la flexibilidad laboral, prioridad que es especialmente intensa en la reforma laboral de 2012, reforma en la que se hace un particular hincapié tanto en este artículo como en el resto del número. Una vez señalados los fines de las reformas se analizan los impactos económicos principales de las mismas. Entre estos el más destacado es la devaluación salarial. Pero también se consideran otros impactos. Para ello nos preguntamos en el artículo si las reformas han servido o no para favorecer el crecimiento económico y el empleo, reducir las fluctuaciones del empleo, aumentar la capacidad generadora de empleo de la economía española o mejorar su competitividad.

Palabras clave: Reformas laborales, flexibilidad laboral, devaluación salarial, umbral de creación de emple, competitividad.

Clasificación JEL: J18, J30, J50.

\section{Abstract}

The aim of the article is to provide a framework for the special issue on the analysis of labour reforms approved at the beginning of the economic crisis from an economic perspective. The paper reviews the common aspects of these reforms, emphasizing the priority of all with respect to the objective of labour flexibility, aim that is particularly intense in the 2012 labour reform. This reform receives a particular emphasis in this article as in the rest of the special issue. Once identified the purpose of the reforms, the main economic impacts of these are analysed. Among others, the most remarkable is the wage devaluation. But the article also considers other impacts: whether the reforms have served to promote the economic and employment growth, to reduce the volatility of employment, to increase the employment generating capacity of the Spanish economy or to improve its competitiveness.

Key words: Labour reforms, Labour market flexibility, Wage devaluation, Threshold of job creation, Competitiveness.

JEL Classification: J24, J41, J45.

C Revista de Economía Laboral 


\section{Introducción. El giro de la política económica en España en la primavera de 2010 y las reformas laborales}

El inicio de la crisis económica en España a comienzos de 2008, un poco más tarde que en el país en el que se desencadena originalmente, EEUU, y en otros países europeo desarrollados, como Alemania y Francia, se extiende en un principio ante el desconcierto y el no reconocimiento de su gravedad por parte del entonces gobierno socialista, lo que retrasa la adopción de medidas de política económica dirigidas a frenarla o a limitarla. Solo tras la reunión del G-20 de noviembre de 2008 y de las recomendaciones a los distintos gobiernos para que reaccionen con políticas destinadas a estimular la demanda efectiva comienza a plantearse la puesta en marcha de medidas correctoras o, al menos, mitigadoras de la crisis. En España no será hasta la primavera de 2009, cuando ya había transcurrido más de un año desde la aparición de los primeros síntomas de la crisis económica, cuando el gobierno aprueba un plan de incentivos fiscales (Plan E) destinado a aumentar el gasto público y frenar el retroceso de la demanda agregada que se estaba produciendo.

Pero apenas había transcurrido un año cuando con la excusa de la crisis griega y el peligro acuciante de una crisis del euro de efectos previsiblemente devastadores cuando las instituciones europeas (Comisión Europea, Eurogrupo y Banco Central Europeo) y otros organismos económicos internacionales muy influyentes (FMI y OCDE) presionan para un giro sustancial de la política económica. Este giro supone pasar de una política keynesiana de demanda, de incentivos fiscales, a una política contraria, neoliberal, de austeridad fiscal brusca y dura, dirigida a recortar gastos públicos y aumentar impuestos, y que, por consiguiente, puede influir negativamente en la demanda agregada, lo que implica abandonar los objetivos de estimular la actividad económica y la creación del empleo, en beneficio del objetivo de reducción del déficit público y de la deuda pública.

Y ello por la creencia generalizada de los economistas neoliberales y de la gran mayoría de los organismos económicos de que la causa de la crisis económica es de índole fiscal y de que una política estricta de consolidación y de acusada austeridad fiscal tendría efectos positivos sobre la mejora de la confianza de los mercados y la reducción de las primas de riesgo de los países que la instrumentaran, lo que, a través del crecimiento económico repercutiría en la reducción del déficit público y de la duda pública. Estas presiones de distintos organismos 
para el cambio de la política económica en Europa se acentúan en la primavera de 2010, especialmente a los países deudores como España, para los que esas presiones, incluso se convierten en amenazas de rescate por parte de las instituciones económicas europeas y del FM. El cambio de la política económica se produjo finalmente en mayo de 2010, con la generalización dentro de Europa de las políticas de austeridad, aunque estás tienen una mayor intensidad en países en los que la financiación empezaba a ser más problemática, como era en el caso español sobre todo por el elevado endeudamiento privado. Pero en este contexto, algunos otros países con moneda propia, como EEUU, se resisten a estos planteamientos y mantienen una política monetaria y fiscal distinta, más preocupada por el empleo que por la reducción del déficit público.

Dos son los problemas principales de este giro de la estrategia económica. El primero, que la crisis fiscal, salvo, posiblemente, en el caso griego, no es la causa de la crisis económica sino uno de los efectos más significativos de la misma (reducción de ingresos públicos y aumento de gastos públicos como los destinados a pagar las prestaciones por desempleo, rescatar la banca o hacer frente al pago de intereses que conlleva el aumento de la deuda pública). Sus causas son más profundas y están más vinculadas con la desregulación financiera y bancaria y de algunos otros mercados que se había venido produciendo desde la década de los ochenta del pasado siglo en consonancia con las políticas neoliberales desarrolladas desde entonces en la gran mayoría de los países desarrollados y con la pérdida de papel y protagonismo del sector público en esos países con efectos de enorme gravedad como la explosión de las burbujas financiera e inmobiliaria. De hecho, en España antes del comienzo de la crisis se producía superávit y no déficit público y la deuda pública apenas superaba la tercera parte del PIB, ya que el problema del endeudamiento no era principalmente público sino privado, de bancos, empresas y hogares familiares, como resultado de la intensidad de las dos burbujas, financiera e inmobiliaria.

$\mathrm{Y}$ el segundo problema del giro sustancial de la estrategia económica era que los efectos positivos que se pregonaban por parte de sus defensores no se produjeron, sino que, al contrario, los mercados cada vez desconfiaron más de economías como la española y las primas de riesgo tuvieron un crecimiento explosivo en el verano de 2012. En realidad, las consecuencias del giro de la política económica hacia una austeridad sin freno fue la del agravamiento de la crisis económica y de que economías como la española, que se habían mantenido durante unos meses fuera de la recesión, en parte, sin duda, 
por influencia de la política keynesiana que se había estado instrumentando, volvieran de nuevo a esa situación de recesión económica (descensos intertrimestrales del PIB) desde principios de 2011 hasta mediados de 2013 en el caso español ${ }^{1}$. Resultado de todo ello, será el mantenimiento de elevados déficits públicos y el aumento continuo de la deuda pública, que roza a mediados de 2015 el $100 \%$ del PIB, cuando al final de 2009 se situaba en el 53,3\%, en vez de disminuir como mantenían y, todavía, mantienen en muchos casos los defensores de las políticas de austeridad

Y conviene tener en cuenta que el final de la recesión en España en el segundo trimestre de 2013 no fue una consecuencia diferida de las políticas de austeridad que pusieron en marcha distintos gobiernos desde 2010 sino que las causas de ese final fueron muy diferentes y, en gran medida, independientes de las políticas aprobadas por las autoridades nacionales. En efecto, las razones fundamentales del final de la recesión económica son de naturaleza exógena tanto a la economía española como a las decisiones gubernamentales, como es el caso del efecto sobre la economía española de la evolución económica más favorable ya desde el segundo trimestre de 2013 de otros países, entre ellos la mayoría de los grandes países europeos; la flexibilidad permitida por las autoridades europeas para el cumplimiento del objetivo del déficit público del $3 \%$ del PIB, que retrasa la fecha de ese cumplimiento desde finales de 2013 a finales de 2016, lo que ha permitido una cierta relajación en la práctica de este tipo de políticas; las declaraciones del presidente del BCE, señor Draghi, de julio de 2012, sin necesidad de tomar entonces ninguna medida, de que iba a hacer todo lo necesario para salvar al euro; la notable depreciación del euro y el fuerte descenso del precio del petróleo que se produce a partir de mediados de 2014; y el cambio a una política monetaria más expansiva del BCE que se anuncia en el otoño de 2014 y se instrumentaliza a principios de 2015 .

Ahora bien, ese cambio de la política económica hacia una estrategia de intensa austeridad fiscal se complementa con otras medidas englobadas en lo que se denominan las "reformas estructurales". En efecto, las autoridades económicas europeas, además de presionar a países deudores como España para que cambien la naturaleza de la política económica e intensifiquen las políticas de austeridad, también les recomiendan la necesidad de aprobar reformas estructurales, imprescindibles, según distintas instituciones económicas internacionales, pero también nacionales, como el Banco de

\footnotetext{
${ }^{1}$ En relación con las políticas de austeridad véase el excelente libro de Blyht (2013).
} 
España, para favorecer el crecimiento económico. De estas reformas las que más éxito tienen entre las autoridades españolas son la bancaria, la de pensiones y la laboral o del mercado de trabajo.

En el caso de las reformas laborales, la necesidad de estas que son sinónimo, como luego se explicará, de desregularización y de reducción de los derechos laborales de los trabajadores, reforzando el poder del empresario y el principio de la libre empresa, se han convertido, no solo desde el inicio de la crisis económica sino prácticamente ya desde la misma aprobación del Estatuto de los Trabajadores de 1980, en una de las obsesiones y mantras principales de los citados organismos económicos y, por consiguiente, en una de las presiones más continuas e intensas de esos organismos a los distintos gobiernos españoles para que las adopten y aprueben ${ }^{2}$.

Las presiones continuaron a finales de 2011, ahora al nuevo gobierno del PP, que aplicó, con ahínco y sin la menor resistencia las políticas de austeridad fiscal, acentuándolas hasta niveles difícilmente soportables social y en muchos casos individualmente, con nuevos recortes del gasto público, especialmente de naturaleza social y en infraestructuras, y aumentos tanto de los impuestos directos como de los indirectos. Al mismo tiempo que se ponían en marcha nuevas reformas estructurales, como la bancaria con cargo, por lo menos en parte, a impuestos, pero también de las pensiones y, otra vez, del mercado de trabajo, como la aprobada en febrero de 2012, apenas dos meses después de la toma de posesión del Gobierno del PP. Esta reforma laboral es, sin duda, la más radical, la más desreguladora y la que más derechos laborales recorta de todas las aprobadas a lo largo no solo de la última crisis sino también desde la restauración de la democracia.

Precisamente, el objetivo de este artículo es el análisis de las reformas laborales aprobadas a partir de 2010, haciendo especial hincapié en sus consecuencias económicas. En el siguiente apartado, el segundo, se consideran los aspectos comunes a todas esas reformas, con una consideración especial a la problemática de la flexibilidad laboral,

\footnotetext{
2 Posiblemente, el principal hito de estas presiones sea la carta conjunta que escriben en agosto de 2011 al entonces presidente del gobierno, señor Zapatero, los gobernadores del Banco Central Europeo, señor Trichet, y del Banco de España, señor Fernández Ordoñez. El efecto de esa carta no solo fue la reforma del artículo 135 de la Constitución para obligar al déficit cero sino también el endurecimiento de la política de austeridad y la aprobación de nuevas reformas laborales. En relación con esta carta, cuyo contenido no se conoció plenamente en su momento, resulta esclarecedor Ekaizer (2012), págs. 121-140.
} 
que se convierte en un objetivo prioritario de todas ellas. Al final de este segundo apartado se analizan los aspectos fundamentales y básicos de la reforma laboral de 2012, a la que se dedica una particular atención en este artículo. Por otra parte, en el tercer apartado se examina el impacto económico más notable de las reformas laborales, sobre todo de la de 2012, la devaluación salarial. En el cuarto apartado se insiste en el resto de los efectos económicos de las reformas laborales, en concreto, en la evolución del PIB y el empleo, en las fluctuaciones de esta segunda magnitud, en la capacidad generadora de empleo de la economía española, o, lo que es lo mismo, en el umbral de crecimiento del empleo, y sobre la competitividad de esa economía. Por último, el artículo se cierra con un apartado, el quinto, en el que se resaltan las conclusiones principales del análisis efectuado.

\section{Las reformas laborales aprobadas durante la crisis económica: aspectos comunes. La flexibilidad salarial}

\section{1. ¿Cuáles fueron esas reformas?}

De las reformas laborales aprobadas por las distintos gobiernos durante la crisis económica destacan tres, las de 2010, 2011 y 2012, la primera y tercera de carácter general, que afectan a diferentes cuestiones y aspectos relacionados con las relaciones laborales y el mercado de trabajo, y la segunda de carácter específico, dedicada a modificar exclusivamente el sistema de negociación colectiva.

La reforma de 2010 se aprobó inicialmente por el Real Decretoley $12 / 2010$, de 16 de junio, de medidas urgentes para la reforma laboral del mercado de trabajo ${ }^{3}$, solo un mes después del giro de la política económica hacia la austeridad fiscal que se produjo el 10 de mayo de ese año. Este Real Decreto-ley se convirtió, después de la correspondiente tramitación parlamentaria, con algún cambio, en la Ley 35/2010, de 17 de septiembre, de igual denominación que el de la norma previa.

\footnotetext{
${ }^{3}$ Con anterioridad a esta norma, el gobierno socialista ya había introducido, una vez iniciada la crisis económica, otras reformas laborales, en concreto, la de fomento de la reducción de la jornada y la suspensión temporal de los contratos por el Real Decretoley 2/2009, de 6 de marzo, de medidas urgentes para el mantenimiento y el fomento del empleo y la protección por desempleo, modificada posteriormente por la Ley 27/2009 de 30 de diciembre, de igual nombre que la norma precedente.
} 
Por su parte, el Real Decreto-ley 7/2011, de 10 de junio, de medidas urgentes para la reforma de la negociación colectiva, introdujo importantes cambios en el sistema de convenios colectivos. En este caso, aunque el gobierno socialista se comprometió en el momento de la convalidación del Real Decreto-ley en el Congreso de los Diputados a tramitarlo posteriormente como Ley, ello no fue posible al adelantarse al 20 de noviembre las elecciones legislativas. Pero esta no iba a ser la última reforma laboral que se aprobara en 2011, ya que el Real Decreto-ley 10/2011, de 26 de agosto, de medidas urgentes para la promoción del empleo de los jóvenes, el fomento de la estabilidad en el empleo y el mantenimiento del programa de recualificación profesional de las personas que agotan su prestación por desempleo, tampoco tramitado legislativamente para convertirlo en ley, introdujo nuevos y relevantes cambios normativos en relación con el mercado de trabajo. Esta norma, que es la respuesta inmediata, junto a la modificación del artículo 135 de la Constitución Española, del gobierno socialista a la carta enviada al señor Zapatero por los gobernadores del Banco Central Europeo y el Banco de España, incluye modificaciones normativas muy sustanciales en materia laboral, como la suspensión de la prohibición del encadenamiento de contratos regulada en 2006 para el mismo trabajador en la misma empresa o grupo de empresa o la considerable flexibilización que se introdujo en el contrato para la formación, denominado a partir de entonces como contrato para la formación y el aprendizaje, en aspectos tales como la ampliación de la edad de contratación hasta los 30 años.

Pero de todas las reformas laborales aprobadas durante la crisis económica la más radical, como se ha señalado, es la que se aprobó, cuando todavía no habían pasado dos meses desde la investidura del nuevo gobierno del PP, primero por el Real Decreto-ley 3/2012, de 10 de febrero, de medidas urgentes para la reforma del mercado laboral, modificado, luego, por la ley 3/2012, de 6 de julio, de igual título que la norma previa. La Ley, aunque mantiene el carácter y la gran mayoría de las medidas inicialmente aprobadas, introdujo algún cambio muy sustancial en relación con el Real Decreto-ley, el más destacado, probablemente, el relativo a la finalización de la ultraactividad, que la ley estableció en un año desde la denuncia del convenio, cuando el Real Decreto-ley la había establecido a partir de los dos años.

Pero, a pesar de la profundidad de la reforma laboral de la Ley $3 / 2012$, esta no ha sido la última aprobada por el gobierno del PP sino que, posteriormente, aprobó varias normas con rango de Real Decretoley que complementaba o, incluso, acentuaba la radicalidad de aquella norma, entre las que destacan, entre otras, el Real Decreto-ley 20/2012, 
de 13 de julio, de medidas para garantizar la estabilidad presupuestaria y de fomento de la competitividad, aprobada solo siete días después que la ley 3/2012, y que, aparte, de una subida inusitada del IVA y de la supresión de la paga extraordinaria de diciembre de los funcionarios, incluyó importantes recortes en materia laboral ${ }^{4}$ y de negociación colectiva ${ }^{5}$. Además, el gobierno del $\mathrm{PP}$ ha aprobado otras normas, siempre por real decreto-ley. que modifican el marco de las relaciones laborales y el mercado de trabajo en un sentido similar de flexibilización del mercado de trabajo, especialmente de la contratación temporal y a tiempo parcial, entre los que se pueden destacar tres: el Real Decreto-ley 4/2013, de 22 de febrero, de medidas de apoyo al emprendedor y de estímulo del crecimiento y de la creación del empleo; el Real Decreto-ley 11/2013, el 2 de agosto, para la protección de los trabajadores a tiempo parcial y otras medidas urgentes en el orden social; y el Real Decreto-ley 16/2013, de 20 de diciembre, de medidas para favorecer la contratación estable y mejorar la empleabilidad de los trabajadores.

\subsection{Objetivos comunes de las reformas aprobadas desde 2010}

Todas estas reformas laborales aprobadas durante la crisis económica tienen una serie de aspectos comunes que, pese a las diferencias de contenido amplitud y ambición, las vincula y relaciona entre sí como si de un proceso prácticamente sin solución de continuidad se tratase ${ }^{6}$.

Un primer aspecto común a estas reformas laborales y, en concreto, a las de 2010, 2011 y 2012 es que, como se ha explicado, han venido precedidas, lo que determina y explica su naturaleza $\mathrm{y}$ contenido, de recomendaciones y presiones de distintos organismos económicos y, específicamente, de la Comisión Europea y de varios gobiernos europeos, entre los que sobresale el alemán, así como, sorprendentemente, por estar la materia laboral tan alejada de sus

\footnotetext{
4 Entre otros muchos los relativos a la protección por desempleo, tanto en el nivel contributivo, al rebajar su cuantía a partir del sexto mes, del $60 \%$ del salario medio de los seis últimos meses anteriores a la pérdida del empleo al 50\%, como en el asistencial al eliminar a los parados de 52 a 55 años de la posibilidad de percibir el subsidio indefinido de los parados de larga duración hasta el cumplimento de la edad ordinaria de jubilación.

5 Como la suspensión o modificación de los convenios colectivos de las distintas administraciones con su personal laboral cuando, por ejemplo, esas administraciones adopten medidas de ajuste o recorte de gasto público.

${ }^{6}$ Un análisis de estos aspectos comunes ya se realizó en Pérez Infante (2013b).
} 
competencias y de las que tendrían que haber sido sus preocupaciones y desvelos principales, del Banco Central Europeo y el Banco de España.

El segundo elemento común de esas reformas laborales aprobadas durante la crisis económica, como de prácticamente todas las que se pusieron en marcha tras el Estatuto de los Trabajadores de 1980, es que se aprobaron inicialmente, independientemente del color político del gobierno, de forma unilateral por el correspondiente gobierno por un real decreto-ley, justificado siempre por los que lo aprobaban por razones de urgencia $\mathrm{y}$, por lo tanto, sin un auténtico debate político ni parlamentario (la convalidación obligatoria en el Congreso de los Diputados no puede considerarse como tal debate), lo que es una clara forma de imposición, muy difícil de superar, aunque, posteriormente, algunas de esas normas se tramitaran parlamentariamente para ser convertidas en leyes. De hecho, la aprobación formal por Ley suele suponer cambios relevantes muy escasos en relación con la aprobación inicial y en algunos casos cuando esos cambios tienen cierta relevancia, como en el caso de la ultraactividad de la reforma de 2012, suponen una mayor dureza y una mayor desregulación en contra de los derechos de los trabajadores. Hasta tal punto condiciona el Real Decreto-ley a la Ley que el título final de esta es siempre el mismo que el inicial que tenía aquel.

El tercer elemento común de todas estas reformas aprobadas a lo largo de la crisis económica, y que está relacionado directamente con la imposición política que supone la aprobación por real decreto-ley, es la ausencia total de consenso social con los interlocutores sociales, en particular con las organizaciones sindicales, que prácticamente en todos los casos de estas reformas laborales aprobadas desde 2010 se han opuesto, al menos aparentemente, frontal y fuertemente a su contenido. Esta falta de consenso social muy generalizada puede condicionar de hecho el propio desarrollo y eficacia de las reformas laborales, en parte, porque en muchas ocasiones la aplicación y desarrollo de las nuevas normas implica la negociación e, incluso, el consenso entre empresarios y trabajadores, lo que resultará muy difícil si, como es el caso, al menos, una de las partes se opone fuertemente a sus objetivos y contenidos.

El cuarto elemento común a las reformas laborales aprobadas durante la crisis económica, que se refiere más a los resultados y consecuencias que al contenido mismo de esas reformas, es que han resultado incapaces e impotentes para mejorar la situación del mercado de trabajo, concretamente del empleo y el paro. Si ya las reformas laborales por sí solas, por su propia naturaleza, es muy difícil que favorezcan la creación de empleo, por ser la demanda de trabajo una 
demanda derivada de la demanda de productos y, por lo tanto, de la actividad económica y la producción, esa dificultad puede convertirse en imposibilidad en una situación de crisis e, incluso de recesión económica, como ocurre en la mayor parte del período 2008-2013, máxime, como es el caso, cuando a las reformas laborales se añade una estricta y rigurosa política de austeridad.

Y, por último, el quinto elemento común de las reformas laborales aprobadas durante la crisis económica, aunque no solo de estas reformas sino también de casi todas las aprobadas desde el Estatuto de los Trabajadores de 1980, es la flexibilidad laboral o desregulación del mercado de trabajo y, en particular, de las relaciones laborales ${ }^{7}$.

La necesidad de una mayor flexibilidad del mercado de trabajo, se ha convertido, como se ha señalado ya, en una obsesión de muchos economistas e instituciones económicas reflejadas en sus reiteradas presiones al gobierno para que actúe todavía hoy en materia laboral y ello independientemente de las numerosas reformas laborales aprobadas a lo largo de las últimas décadas y de la situación actual después de la reforma de 2012 de acusada desregulación y de desequilibrio entre las distintas contrapartes del mercado de trabajo, como, incluso, se deduce de distintos indicadores internacionales ${ }^{8}$.

\footnotetext{
7 Es cierto que algunas de las reformas laborales aprobadas desde 1980 incluyen medidas teóricamente dirigidas a limitar la contratación temporal, pero en el conjunto de esas reformas la inclusión de otras medidas diferentes, especialmente las relacionadas con el despido y la modificación de las condiciones de trabajo y salariales provoca que sea la flexibilidad el aspecto común predominante. Únicamente las reformas de 1998 y 2006 pueden considerarse ajenas a ese planteamiento. La reforma de 1998, aprobada por el Real Decreto-ley 5/1998, el 17 de noviembre, de medidas urgentes para la mejora del mercado de trabajo en relación con el trabajo a tiempo parcial y el fomento de su estabilidad, que el ministro de trabajo de entonces, Señor Arenas, pactó con los sindicatos UGT y CCOO y con la oposición de las organizaciones empresariales CEOE y CEPYME, tuvo como objetivo exclusivo la contratación a tiempo parcial, estableciendo nuevas limitaciones y condiciones. Y, por su parte, la reforma de 2006, aprobada, primero, por el Real Decreto-ley 5/2006, de 9 de junio, para la mejora del crecimiento y del empleo y, después por la Ley 43/2006, de 29 de diciembre, tenía como finalidad principal priorizar la contratación indefinida y fue pactada por el gobierno socialista con las organizaciones empresariales CEOE y CEPYME y los sindicatos UGT y CCOO.

8 Especialmente, los referidos al despido y la contratación como se infiere de OCDE (2014).
} 


\subsection{La flexibilidad laboral en la teoría económica}

Y este discurso insistente en la necesaria flexibilización tiene su base principal en el análisis que efectúa la teoría económica ortodoxa, tanto la neoclásica como la neokeynesiana ${ }^{9}$, que considera el mercado de trabajo como si fuera el de una mercancía cualquiera, en el que la cantidad intercambiada, el empleo, y su precio, el salario, se determinan por la relación entre la oferta, y la demanda de trabajo. De hecho, el análisis del mercado de trabajo que realiza la economía ortodoxa parte de un modelo "ideal", basado en el supuesto de un mercado perfectamente competitivo y en el que se garantiza una perfecta flexibilidad salarial, de modo que los salarios reales aumentarán cuando la demanda de trabajo supera a la oferta y disminuirán cuando sea la oferta la que supere a la demanda.

En este modelo "ideal", que hace completa abstracción de la consideración del mercado de trabajo como una institución social, al centrarse en una relación de intercambio entre "cosas", entre una mercancía, el trabajo, y el dinero, el salario, la situación normal, tendencial, será la del pleno empleo porque en el equilibrio a largo plazo $^{10}$ el salario, al ser plenamente flexible, igualaría la demanda y la oferta de trabajo. En este modelo, solo podrá existir paro, según los economistas que lo defienden, si este es voluntario, o sea, si existen trabajadores que únicamente desean trabajar a un salario superior al del mercado o si no se cumplen las hipótesis de que el mercado sea perfectamente competitivo y los salarios sean totalmente flexibles, especialmente a la baja cuando la oferta supera a la demanda de trabajo.

Por lo tanto, la existencia del paro según la economía ortodoxa se explicaría, principalmente, aparte de la mayor o menor importancia del considerado por los economistas ortodoxos como paro voluntario y haciendo abstracción de las variaciones estacionales y a corto plazo, por la existencia de "imperfecciones" o "perturbaciones" en el mercado de trabajo, que lo alejaría del modelo "ideal", de un mercado perfectamente competitivo y en el que los salarios serían plenamente

\footnotetext{
${ }^{9}$ Aunque en la escuela neokeynesiana la demanda agregada y el Estado representan un papel que no tienen en la neoclásica, el análisis del mercado de trabajo basado en la flexibilidad no es muy diferente en las dos corrientes de la economía, siempre dejando claro que estos economistas no incluyen a los llamados "postkeynesianos" con planteamientos muy diferentes.

10 En los análisis más radicales, como el de las expectativas racionales, ello ocurrirá, incluso, a corto plazo.
} 
flexibles. Es decir, el paro se explicaría, sobre todo, por la existencia de rigideces, regulaciones y problemas de funcionamiento de ese mercado y cuanto mayores sean más elevado e intenso será el desempleo.

Ahora bien, la economía ortodoxa suele precisar cuáles son esas "perturbaciones" o elementos "perturbadores" explicativos de que una economía pueda tener niveles de paro elevados, aunque lo califiquen de natural, estructural o de equilibrio. Y entre esos elementos que se suelen citar con mayor frecuencia para explicar la importancia de ese tipo de paro figuran la existencia de sindicatos, la determinación de los salarios y de las condiciones de trabajo a través de la negociación colectiva, en lugar de por las fuerzas de la oferta y la demanda de trabajo, y la existencia de regulaciones legales, como el establecimiento de un salario mínimo legal, la limitación de la contratación temporal o del despido o la misma presencia de un sistema de prestaciones por desempleo.

Pero lo que la economía ortodoxa destaca como "imperfecciones" o elementos "perturbadores" son en realidad algunas de las características más relevantes de las sociedades actuales más desarrolladas, que, incluso, identifican muchas veces a esas sociedades, como la existencia de sindicatos y de la negociación colectiva, la regulación legal propia del derecho del trabajo o la protección específica por desempleo ${ }^{11}$. Porque, el problema está en el origen, al considerar al mercado de trabajo como el mercado de una mercancía cualquiera cuando la relación entre el salario y el empleo es en esencia una relación social de carácter laboral entre agentes sociales, empresarios y trabajadores, en definitiva entre distintas clases sociales.

Si las rigideces y el defectuoso funcionamiento del mercado de trabajo impiden que los salarios bajen cuando existen niveles elevados de paro, este será, según la economía ortodoxa, un problema persistente y cuanto mayores sean esas rigideces e imperfecciones más alta será su importancia por lo que las diferencias entre los distintos países en cuanto a niveles e intensidades del desempleo se explicarán, fundamentalmente, por las diferencias en cuanto a esas rigideces del mercado de trabajo. Es más, la mayoría de los economistas ortodoxos centran sus explicaciones de los elevados niveles de paro de una economía como la española, más que por la situación y evolución de la actividad económica y por la naturaleza del modelo productivo, por la existencia de importantes rigideces en el mercado de trabajo y por su deficiente funcionamiento.

11 En relación con el análisis de las escuelas ortodoxas sobre el mercado de trabajo puede verse Pérez Infante (2013a). 
Con base en este tipo de análisis del mercado de trabajo, en mi opinión claramente ideológico, muchos economistas y la mayoría de los organismos económicos propugnan para las economías que padecen de forma más intensa el problema del desempleo, como de forma destacada ocurre con la economía española, la necesidad de reformas laborales, de cambios de las distintas instituciones del mercado de trabajo.

Y, aunque los objetivos declarados por los gobiernos que han aprobado las últimas reformas laborales sean fines tan deseables como elevar la capacidad generadora de empleo de la economía española y reducir la dualidad del mercado de trabajo entre la contratación indefinida y la temporal parece que los objetivos reales sean otros distintos por el tipo de medidas aprobadas y porque su aplicación puede afectar al equilibrio de las relaciones laborales y, en particular, al poder de los distintos sujetos de esas relaciones, empresarios y trabajadores.

En este sentido, las medidas más generalizadas de las reformas laborales aprobadas durante la crisis económica han ido dirigidas a conseguir una mayor flexibilidad externa de las empresas, a través de la mayor facilidad y abaratamiento de la contratación y el despido y así permitir más posibilidades a las empresas de cambiar el tamaño de las plantillas; una más acusada flexibilidad interna de las empresas, favoreciendo las modificaciones de las condiciones de trabajo, incluidas las salariales, se hayan o no pactado en convenios colectivos; o una más elevada flexibilidad salarial, no solo a través de las mayores posibilidades de modificar las condiciones salariales sino también a través de reformas de la negociación colectiva tendentes a debilitar la capacidad negociadora de los trabajadores.

\subsection{La reforma laboral de 2012}

Pero ya se ha reiterado que de todas las reformas laborales aprobadas a lo largo de la crisis la más amplia, ambiciosa, intensa y radical ha sido la de 2012 . En esta reforma se consideraron numerosas medidas destinadas, a aumentar la flexibilidad laboral, en sus tres vertientes, externa, interna y salarial. En relación con la flexibilidad externa, la reforma de 2012 introduce importantes cambios en materia de contratación y despido. En lo que respecta a la contratación, en vez de tender a reducir la elevada precariedad del empleo existente en España ${ }^{12}$, se crea un nuevo contrato, en principio indefinido, llamado

\footnotetext{
12 La reforma laboral de 2012 es una de las pocas reformas de las aprobadas a partir de
} 1984, año en el que se flexibilizó notablemente la contratación temporal, que no 
sin fundamento alguno de emprendedores, dirigido a las empresas de menos de 50 trabajadores, cuya característica principal es un período de prueba de un año, durante el cual el empresario puede despedir al trabajador sin causa ni indemnización alguna, lo que le acerca más a un contrato temporal no causal que a uno indefinido. Además, la reforma laboral de 2012 incluye otras medidas tendentes a la mayor flexibilidad y precariedad del empleo, como la ampliación de las posibilidades del contrato para la formación y el aprendizaje de jóvenes trabajadores no cualificados ${ }^{13}$ y la posibilidad de realizar horas extraordinarias en el contrato a tiempo parcial ${ }^{14}$, medidas estás que pueden desnaturalizar los distintos objetivos y características de estos dos tipos de contratos.

Y, también, dentro de las mayores posibilidades de flexibilidad externa, son muy relevantes los cambios que tienen como finalidad facilitar y abaratar el despido de los trabajadores contratados indefinidamente. En concreto, se favorece considerablemente el despido procedente por causas económicas, todavía más que lo que ya se había

establece ninguna medida dirigida a limitar ese tipo de contratación. De hecho, la única medida que tiene alguna relación con este fin, la finalización del período de suspensión de la prohibición del encadenamiento de la contratación temporal, previsto en la reforma laboral de 2006, aprobada por el gobierno socialista de entonces con consenso con las organizaciones patronales, CEOE y CPYME, y sindicales, CCOO y UGT, se compensa con creces con el cambio del cómputo de los períodos exigidos para convertir la contratación temporal en indefinida en el caso de que se produzca el encadenamiento de los contratos temporales. Para un análisis de naturaleza jurídica que sintetiza los problemas fundamentales de la reforma laboral de 2012 puede consultarse Casas Baamonde, Rodríguez-Piñero Bravo-Ferrer y Valdés Dal-Rê (2012). Y para un análisis económico de esa reforma puede consultarse Malo (2012a) y (2012b) y Pérez Infante (2015a).

13 Manteniendo los cambios establecidos por el Real Decreto-ley 12/2011, de agosto, como la ampliación de la edad de contratación a los 30 años, e yendo, incluso, más allá en la línea de la flexibilización de esta modalidad de contratación al permitir, entre otros cambios, el encadenamiento sucesivo de varios contratos para la formación y el aprendizaje con el mismo trabajador en la misma o distintas empresas hasta que alcance la edad de 30 años.

14 La posibilidad de realizar horas extraordinarias en los casos de contratos a tiempo parcial se eliminó en 1998, sustituyendo esas horas extraordinarias en los casos de contratos a tiempo parcial indefinidos por las horas complementarias creadas en ese año. Pero la reforma de 2012 restituyó esa posibilidad, sin modificar las posibilidades de las horas complementarias para los contratos a tiempo parcial indefinido. Posteriormente, el Real Decreto-ley 16/2013, de 30 de diciembre, volvió a suprimir la posibilidad de realizar horas extraordinarias en este tipo de contratos, pero mantiene las posibilidades de superar la jornada ordinaria, favoreciendo la realización de las horas complementarias, que, incluso se permiten para los contratos a tiempo parcial temporal. 
hecho en la reforma de 2010, al ampliar notablemente esas causas ${ }^{15}$, permitiendo este tipo de despido sin necesidad de que la empresa obtenga pérdidas presentes o futuras, se facilita el despido colectivo al suprimir la autorización administrativa y se abarata sustancialmente el despido improcedente al rebajar la indemnización desde 45 días de salario por año de servicio con un tope de 42 mensualidades a 33 días con un límite de 24 mensualidades ${ }^{16}$.

En cuanto a la flexibilidad interna, que ya había sido favorecida en 2009, con ayudas públicas a las empresas y mejoras de las prestaciones por desempleo en los casos de suspensión temporal del contrato y de reducción de la jornada laboral, y en 2010, favoreciendo la modificación de las condiciones de trabajo y permitiendo una mayor movilidad funcional y geográfica de los trabajadores dentro de la empresa, la reforma laboral de 2012 introduce también cambios sustanciales. Uno de los cambios más sustanciales y radicales de esa reforma laboral, en la dirección de propiciar la libertad de empresa, es la posibilidad de que las empresas pueden modificar condiciones de trabajo, incluida la cuantía del salario, unilateralmente, sin apenas justificación ${ }^{17}$, cuando esas condiciones no estén acordadas en convenio colectivo o cuando las supere o mejore. Asimismo en la misma línea del despido, la reforma de 2012 facilita también la suspensión temporal del contrato y la reducción de la jornada laboral ${ }^{18}$.

$\mathrm{Y}$, en relación con la flexibilidad salarial, el cambio de mayor relevancia es el ya citado de la posibilidad de modificar la cuantía salarial, reduciéndola, por decisión unilateral del empresario, sin

15 La reforma laboral de 2010 había ampliado las causas económicas para el despido procedente, considerando que se presentan estas causas cuando se produzcan pérdidas, se prevean que pueden producirse en el futuro o, incluso, aunque no se encuentre la empresa en esas situaciones, cuando se reduzcan persistentemente los ingresos o las ventas de la empresa. La reforma de 2012, por su parte, concretó esa reducción de ingresos o ventas cuando se produzca en términos interanuales durante tres trimestres sucesivos.

${ }^{16}$ Lo que supone que la cuantía del despido improcedente en relación con la del despido procedente pasa de representar 2,5 veces antes de la reforma laboral de 2012 a 1,65 veces después. El límite máximo de mensualidades pasa de 3,75 veces a dos veces.

17 Bastando con que existan razones, sin precisar cuáles, relacionadas con la competitividad, productividad u organización técnica o del trabajo, en las empresas. La generalidad y la falta de concreción de las causas significa de hecho una gran libertad para que los empresarios modifiquen las condiciones de trabajo.

18 Profundizando en los cambios que ya se habían producido en 2009 y 2010. En concreto, suprimiendo la necesidad de la autorización obligatoria cuando tengan carácter colectivo y ampliando las causas económicas justificativas, bastando con que se haya producido una reducción de los ingresos durante dos trimestres consecutivos, uno menos que en el supuesto de despido procedente. 
ningún tipo de consenso con los trabajadores, cuando esa cuantía no esté fijada por convenio colectivo estatutario o supere a la del convenio, por haberse establecido en los contratos individuales con los trabajadores, en acuerdos o pactos distintos a esos convenios o en virtud de decisión individual del empresario con efectos colectivos para los trabajadores de las empresas.

Pero también en el caso de que la empresa esté sujeta a convenio colectivo se refuerzan en 2012 las posibilidades de modificar el salario acordado. Ya que, aunque, sea necesario el acuerdo de empresa y de trabajadores, se amplían notablemente las causas que justifica el descuelgue salarial o inaplicación de lo pactado en el convenio correspondiente ${ }^{19}$, al bastar, como en el caso de la suspensión temporal del contrato y la reducción de la jornada laboral, con una disminución de los ingresos durante dos trimestres sucesivos ${ }^{20}$.

Además de esta sustancial modificación, la reforma laboral de 2012 introduce otras dos también muy relevantes en la normativa de la negociación colectiva, que puede influir tanto en su debilitamiento como en la mayor flexibilidad salarial. Concretamente, la prioridad aplicativa de los convenios de empresa en distintas materias, entre las que se encuentra la salarial, sobre otros convenios que sean de aplicación a la empresa, modificándolos, sin que pueda existir pacto en contrario ${ }^{21}$, y el final de la ultraactividad ${ }^{22}$ cuando haya transcurrido un año desde la denuncia del convenio y, por lo tanto, desde el final de su vigencia.

Todas estas medidas relativas a los convenios colectivos afectan sustancialmente a la propia naturaleza de la negociación colectiva, debilitándola, sobre todo en las pequeñas y medianas empresas, en las que el grado de afiliación sindical de los trabajadores es muy escasa y la dependencia de los trabajadores respecto de los empresarios muy elevada. En relación con estos cambios de la reforma laboral de 2012 cabe hacer algunas reflexiones. Por un lado, el final de la ultraactividad

\footnotetext{
19 Las posibilidades de descuelgue o inaplicación del convenio en materia salarial se extiende en la reforma de 2012 al resto de las condiciones de trabajo.

${ }^{20}$ Otro cambio que introduce la reforma de 2012 se refiere a la circunstancia en que se mantengan discrepancias entre empresa y trabajadores, al permitir que cualquiera de las partes podrá someter a la Comisión Consultiva Nacional de Convenios Colectivos o a la correspondiente comisión autonómica el arbitraje obligatorio de las citadas discrepancias.

21 La reforma de 2011 también preveía la prioridad aplicativa de los convenios de empresa pero estaba condicionada a que no existiera pacto en contrario en acuerdos institucionales o convenios nacionales o autonómicos. Esta posibilidad de pacto en contrario se elimina en la reforma de 2012.

22 Prórroga indefinida de la vigencia temporal del convenio colectivo hasta la firma de uno nuevo.
} 
cuando haya transcurrido un año desde el final de la vigencia del convenio anterior puede dejar a una parte importante de trabajadores sin convenio, aparte de que la negociación de un nuevo convenio partiría de cero, puesto que las condiciones pactadas en convenios anteriores habrían decaído, lo que en situaciones en las que la capacidad negociadora de los trabajadores se ha debilitado, como ocurre en la actualidad por los efectos de la crisis en el empleo y el paro y por las propias consecuencias de las reformas laborales, pudiera ocurrir que las condiciones de trabajo y salariales de los trabajadores empeoraran sustancialmente.

Y, por otro lado, respecto de la descentralización de la negociación colectiva, que parece deducirse de la prioridad aplicativa de los convenios de empresa, puede que, al contrario de lo que sostienen los economistas ortodoxos y las organizaciones económicas que la propician, los resultados económicos del conjunto de la economía no mejoren sino que empeoren. Y esto es lo que parece deducirse de distintos estudios de la división laboral de la OCDE (no así de la económica) en sus informes anuales de Perspectivas de empleo, que resaltan que no existe evidencia empírica contundente que respalde dicha mejora (es decir, que los resultados sean más positivos cuanto mayor sea la descentralización de los convenios colectivos) y que lo verdaderamente relevante para esa mejora no es el grado de descentralización sino el de coordinación de la negociación colectiva y, además, que parece que en las últimas décadas en los países en los que se ha procedido a descentralizar la negociación colectiva el empleo ha evolucionado más negativamente que en los países que no lo han hecho ${ }^{23}$.

Todos estos cambios introducidos por la reforma de 2012 implican una importante desregulación y flexibilidad del mercado de trabajo y de las relaciones laborales, predominando la potenciación del principio de la libertad de empresas y el sometimiento de la normativa laboral a las exigencias del mercado, con base al ideario y a los fundamentos teóricos de la economía neoliberal. De todo ello resultará un mayor desequilibrio en el conjunto de las relaciones laborales entre empresarios y trabajadores, en beneficio de los primeros y en detrimento de los segundos ${ }^{24}$

23 Véanse distintos informes de Perspectivas del Empleo de la OCDE. En concreto, OCDE (1997), (2004) y (2006). También puede consultarse Pérez Infante (2013c).

${ }^{24}$ Un planteamiento de esta naturaleza puede verse en Guamán Hernández e Illueca Ballester (2012) 


\section{El impacto económico más sobresaliente de las reformas aprobadas durante la crisis: la devaluación salarial}

Los defensores tanto de las políticas de austeridad como de las reformas laborales pronosticaban y todavía mantienen que los resultados económicos de esas estrategias serían muy favorables tanto en la producción como en el empleo. Las políticas de austeridad porque, como se señala en la introducción, casi inmediatamente mejorarían la confianza de los mercados en la economía española y reducirían la prima de riesgo con el consiguiente abaratamiento de la financiación del conjunto de la economía. Y las reformas laborales porque la amortiguación o desaparición de las imperfecciones del mercado de trabajo y la mayor flexibilidad salarial y del empleo que se conseguiría serviría para abaratar los salarios y reducir los costes laborales unitarios, mejorando la competitividad de la economía española y aumentando la producción y el empleo. Aparte de que se amortiguarían las rigideces que, según los defensores de esas reformas, limitan y condicionan la creación de empleo. Pero parece que el efecto más inmediato de las estrategias basadas en la austeridad y en la necesidad de reformas laborales cada vez más ambiciosas e intensas ha sido más bien el agravamiento de la situación de crisis económica ${ }^{25}$, y el mayor debilitamiento de la capacidad negociadora de los trabajadores con el consiguiente fenómeno de la devaluación salarial, que por sí misma, como luego se explicará, no ha servido para conseguir los resultados económicos positivos que se propugnaban. ${ }^{26}$.

La devaluación salarial, consecuencia de la mayor flexibilidad salarial que se ha venido produciendo en los últimos años, se refleja directamente en la moderación de los salarios pactados en los convenios colectivo, pero todavía más intensamente en la evolución de los salarios brutos percibidos por los trabajadores, estimados por el coste salarial por trabajador de la Encuesta Trimestral de Coste Laboral (ETCL) del INE. De hecho, los salarios brutos por trabajador disminuyen en términos monetarios o nominales desde finales de 2012 y en términos reales (deflactados por el IPC) desde 2010, lo que ha supuesto una

\footnotetext{
$25 \mathrm{Al}$ provocar o, al menos, favorecer la entrada en una nueva recesión económica, que se inició a principios de 2011 y finalizó a mediados de 2013.

26 Este fenómeno se analiza en Pérez Infante (2013b), (2013c), (2013d), (2015a) y (2015b).
} 
pérdida del poder adquisitivo del conjunto de los trabajadores en el período 2010-2014 de más de siete puntos porcentuales.

Esta evolución del coste salarial por trabajador coincide con la del coste laboral por trabajador (también estimado por la ETCL) ${ }^{27}$ y de su equivalente la remuneración por asalariado de la Contabilidad Nacional de España (CNE). Pero, incluso, el coste laboral unitario nominal ${ }^{28}$ o coste laboral por unidad de producción (CLU), que es un concepto más significativo para el empresario que el coste laboral por trabajador, por comparar el coste que tiene para el empresario la contratación de un trabajador con su contribución a la producción, disminuye desde antes, desde 2010. Asimismo, desde 2010 disminuye el coste laboral unitario real ${ }^{29}$.

Pues bien, este proceso de devaluación salarial, junto al fuerte aumento del paro que se produce desde el inicio de la crisis económica, y que, como luego se explicará, no se corrige ni por las políticas de austeridad ni por las reformas laborales, sino que se acentúa desde el giro de la política económica en la primavera de 2010, trae consigo la importancia creciente del fenómeno de los trabajadores pobres y contribuye de forma notable a que España sea el país de toda la zona del euro en que más aumenta la desigualdad durante la crisis económica y el país, después de Lituania, con mayor desigualdad actualmente de toda la UE.

Ello se constata con dos series de datos, la pérdida de la participación de las rentas salariales en el PIB, por un lado, y el aumento de la dispersión salarial, por otro lado. En cuanto a la primera, se constata, en efecto, una pérdida del peso relativo de la masa salarial o remuneración de los asalariados en el PIB con las estimaciones de la CNE, que se concreta en un retroceso del mismo desde 2009, el 51,3\%, a 2014, el $47.1 \%$, de 4,2 puntos porcentuales menos, el $8.2 \%$ en términos relativos. De este descenso, 0,5 puntos se deben a la reducción de la tasa de asalariados, porcentaje de

27 Que se obtiene añadiendo al coste salarial por trabajador la aportación del empresario a la seguridad social y otros pagos no salariales a los trabajadores, como la indemnización por despido o la compensación por finalización de contrato.

28 Calculado por la Contabilidad Nacional como cociente entre la remuneración por asalariado y la productividad por ocupado.

${ }^{29}$ Coste laboral unitario nominal deflactado por el deflactor del PIB, indicador de los precios de la producción interior, y, por lo tanto, igual al cociente entre el CLU nominal y el deflactor del PIB. Abreviadamente:

$\mathrm{CLUr}=\mathrm{CLUm} / \mathrm{P}=\mathrm{RPAs} / \mathrm{pr} \times \mathrm{P}$, dónde CLUr y CLUm

son, respectivamente, el coste laboral unitario real y el coste laboral unitario monetario, $\mathrm{P}$ el deflactor del PIB, RPAs la remuneración por asalariado y por la productividad por ocupado. 
asalariados sobre el total de ocupados, que disminuye el $0,5 \%^{30}$. Y, el resto, 3,7 puntos porcentuales, se debe al descenso de los costes laborales unitarios reales, con una caída superior al $7 \%$ en términos relativos, lo que se puede entender que es consecuencia de la devaluación salarial ${ }^{31}$.

Y el segundo tipo de datos, los relacionados con la dispersión salarial, se pueden obtener de la estadística del INE de Deciles Salariales de la EPA, que proporciona información desde 2006 a 2013. Según estos datos, la devaluación salarial se concentra en los trabajadores con salarios más bajos, en concreto en el $30 \%$ que menos gana, y, además, el aumento de los salarios está relacionado directamente con su cuantía, cuanto mayor sea el nivel salarial mayor el crecimiento y cuanto menor el nivel mayor el retroceso, de modo que, si en 2007 el salario medio del 10\% que más ganaba era 7,3 veces el salario medio del 10\% que menos ganaba, en 2010 esa proporción era de nueve veces y en 2013 de doce. Por otra parte, a lo largo de la crisis se constata que el salario medio se reduce principalmente en los trabajadores con menores niveles salariales que llevan menos tiempo trabajando en la empresa y, sobre todo, en los que han sido contratados a lo largo del último año, los que menor antigüedad tienen.

Pero la devaluación salarial no era ningún objetivo expresamente declarado por los gobiernos en ninguna de las reformas laborales aprobadas durante la crisis y, desde luego, no lo era en la aprobada en $2012^{32}$, mientras que los objetivos declarados realmente eran otros muy diferentes, como la creación de condiciones favorables para el crecimiento económico y el empleo, el aumento de la capacidad generadora de empleo de la economía española, la reducción de las

${ }^{30}$ Que disminuye desde 2009 a 2014 del 86,5\% al 86,0\%.

${ }^{31} \mathrm{El}$ porcentaje que representa la renta de los asalariados en el PIB nominal equivale al producto del CLUreal por la tasa de asalarización. Expliquemos esa relación:

$\% \mathrm{RA}_{\mathrm{s}} / \mathrm{PIB}_{\mathrm{m}}=\mathrm{RPA}_{\mathrm{s}} \times \mathrm{A}_{\mathrm{s}} / \mathrm{PIB}_{\mathrm{r}} \times \mathrm{P}=\mathrm{RPA}_{\mathrm{s}} \times \mathrm{A}_{\mathrm{s}} / \mathrm{p}_{\mathrm{r}} \times \mathrm{PO} \times \mathrm{P}=\mathrm{RPA}_{\mathrm{s}} / \mathrm{p}_{\mathrm{r}} \times \mathrm{P} \times \mathrm{A}_{\mathrm{s}} / \mathrm{PO}=\mathrm{CLU}_{\mathrm{r}} \times$ tas , dónde $\mathrm{RA}_{\mathrm{s}}$ es la remuneración de asalariados, $\mathrm{PIB}_{\mathrm{m}}$ es el PIB monetario, RPAs la remuneración por asalariado, As la población asalariada, $\mathrm{PIBr}$ el $\mathrm{PIB}$ real, $\mathrm{P}$ el deflactor del PIB, pr la productividad por ocupado, PO la población ocupada y tas la tasa de asalariados. Las variables relacionadas con el empleo están en términos equivalentes al tiempo completo.

32 Aunque el gobierno del PP no consideraba como uno de los objetivos de la reforma laboral de 2012 la devaluación salarial, esta se consideraba como una de las principales consecuencias de la reforma en la Actualización del Programa de Estabilidad enviado a la Comisión Europea en la primavera de 2012, al poco, por lo tanto, de aprobarse la reforma en febrero por el Real Decreto ley 3/2012. En relación con los objetivos de las reformas laborales y los efectos imprevisibles de esas reformas véase Toharia y Malo (2009). 
segmentaciones laborales entre empleos indefinidos y temporales o el mejor funcionamiento del mercado de trabajo. Está claro que a la hora de hacer balance de las reformas laborales el objetivo real es muy relevante.

\section{La reforma laboral de 2012 , verdaderamente ¿ha tenido unos resultados positivos?}

\subsection{Consideraciones previas}

Como la reforma laboral de 2012 (considerando como tal también a todos los cambios normativos posteriores que la complementan) fagocita y absorbe a todas las anteriores, aparte de su mayor profundidad, amplitud y ambición y de que afecta a una parte muy importante de la normativa laboral, en particular del Estatuto de los Trabajadores, parece adecuado que al evaluar las reformas laborales aprobadas durante la crisis económica se dé especial relevancia a los efectos de esa reforma.

Es lo que se hace en Pérez Infante (2015a), cuando se analizaba el impacto económico de las reformas laborales aprobadas durante la crisis económica y se hacía especial referencia a las consecuencias de la reforma de 2012. En este artículo abordaremos la cuestión de una forma algo diferente, en vez de ir analizando los distintos efectos derivados de la aplicación de las reformas laborales, nos preguntaremos si las reformas y, desde luego, la devaluación salarial que ha sido un fenómeno incuestionable derivado de esa aplicación han tenido los efectos positivos que mantenían las autoridades políticas antes de su aprobación y que mantienen ahora, después de varios años de aplicación ${ }^{33}$. Es decir, nos preguntamos si las últimas reformas laborales y, en particular, la de 2012 y posteriores, las aprobadas por el gobierno del PP, han servido para aumentar la producción y el empleo, o, al menos, para crear las condiciones para que así sea en el futuro, para reducir las fuertes oscilaciones y fluctuaciones del empleo, para recortar el nivel e intensidad del paro, para aumentar la capacidad generadora de empleo de la economía española o para mejorar la competitividad de esa economía.

\footnotetext{
33 Sin apenas haber transcurrido un año desde la aprobación de la reforma laboral distintos organismos oficiales evaluaron muy positivamente la reforma laboral de 2012 . En concreto, se hicieron evaluaciones positivas en Banco de España (2013), Ministerio de Empleo y Seguridad Social (2013) y OCDE (2014), esta última realizada por encargo del Ministerio de Empleo y Seguridad Social.
} 
Porque no parece que el método utilizado en algunas de las evaluaciones positivas que se han efectuado de las reformas laborales, concretamente de la de 2012, comparando la situación posterior a esa reforma con la situación que se hubiera producido en los mismos años sin la aprobación de la reforma, sea el más adecuado y objetivo para cuantificar los efectos de la misma. Y ello porque este tipo de comparación, que parece más un ejercicio matemático, basada en modelos de regresiones, es decir, prolongando la tendencia anterior ${ }^{34}$, está presuponiendo que la evolución posterior a la aprobación de la reforma laboral solo se diferencia de la anterior por la influencia de esa reforma y de que la tendencia de la evolución anterior se mantendría idéntica a partir de 2012 en ausencia de la reforma laboral sin tener en cuenta que los períodos considerados como bases de las proyecciones en este tipo de evaluaciones son muy desiguales no solo desde el punto de vista cíclico sino también desde el punto de vista de las políticas económicas arbitradas, que pueden ser muy diferentes, y de que las meras proyecciones de los períodos anteriores bajo la hipótesis de que el comportamiento futuro sería igual que el pasado o el presente suponen una simplificación muchas veces burda de la realidad mucho más compleja.

En lo que sigue, y teniendo en cuenta que es muy difícil y problemático separar los efectos de las reformas laborales y, dentro de ellas, la de 2012, de la propia situación de crisis económica y de otras medidas aprobadas como las dirigidas a la austeridad fiscal, vamos a proceder a analizar, desde un punto de vista meramente descriptivo, analizando las estadísticas disponibles y sin utilizar procedimientos econométricos, si es incontestable que esas reformas laborales y, en particular, la de 2012 ha tenido efectos positivos en una serie de cuestiones fundamentales en relación con los resultados económicos y de empleo.

\footnotetext{
34 Este es el caso de las evaluaciones de Ministerio de Empleo y de Seguridad Social (2013) y OCDE (2014). La primera evaluación compara los resultados reales del período que transcurre entre el segundo trimestre de 2012 y el primero de 2013 con las previsiones que se obtienen para ese período con base en la serie que abarca desde el primer trimestre de 1980 hasta el primer trimestre de 2012. En el segundo estudio existe una gran confusión y ambigüedad sobre el período base considerado, ya que utiliza en su evaluación diferentes ecuaciones y no siempre el período es el mismo. Aunque nunca se precisa claramente el período parece que se inicia en torno a 2006 y termina en el cuarto trimestre de 2011.
} 


\subsection{Evolución del PIB y el empleo, ¿mejora a partir de la reforma laboral de 2012?}

La primera cuestión será si la reforma laboral de 2012 ha tenido efectos positivos en el PIB o, lo que es lo mismo, si la tasa de variación del PIB real o en volumen ha sido menos negativa como consecuencia de esa reforma. Lo primero que se constata es que, si bien el mayor descenso del PIB se produjo en 2009, con el $-3,6 \%$, el retroceso del PIB en 2012 y $2013,-2,6 \%$ y $-1,7 \%$, respectivamente, es muy superior al que se produjo en 2010, en el que se mantuvo constante el PIB (variación del $0 \%$ ), y al que se produjo en 2011, cuando se redujo el 1\%. Por otra parte, los descensos del PIB en España de 2012 y 2013 son muy superiores a los de la zona del euro (-0,8\% y $-0,2 \%$, respectivamente), el conjunto de la UE (-0,5\% y $0,2 \%)$ y la OCDE (1,3\% y $1,2 \%)$. Parece obvio que el giro hacia una política de austeridad en la primavera de 2010 es la causa de ese peor comportamiento de la actividad económica en España, que también se produce en otros países europeos que siguen el mismo tipo de estrategia económica, aunque con menor intensidad.

En todo caso, si se utilizan las variaciones intertrimestrales del PIB real, corregido de efectos estacionales y de calendario, se aprecia como desde el inicio de la crisis se distinguen cuatro fases distintas de esta evolución: la primera, después de unos trimestres de desaceleración, que va desde el tercer trimestre de 2008 al cuarto de 2009 de evolución negativa, la segunda, desde el primer trimestre de 2010 al cuarto del mismo año de evolución positiva, la tercera, desde el primer trimestre de 2011 al segundo trimestre de 2013 de evolución otra vez negativa, destacando el retroceso del cuarto trimestre de 2012 , con una variación intertrimestral del $-0,8 \%$, y la cuarta fase que comienza en el tercer trimestre de 2013, período en el que finaliza la recesión, y la variación intertrimestral del PIB retorna a valores positivos.

De esta evolución destaca el comportamiento positivo de la tasa de variación intertrimestral que comienza a principios de 2010, inferido, sin duda, por la política de incentivos fiscales iniciada en la primavera de 2009, y la vuelta al comportamiento negativo a partir del primer trimestre de 2011, cuando ya se detectan las consecuencias del giro hacia una intensa política de austeridad en la primavera de 2010. Con la aprobación de la reforma laboral en febrero de 2012 la situación no cambia sino que, incluso, se hace todavía más negativa. Y, por otra parte, como se ha señalado, solo factores exógenos a la economía española, como la mejor situación económica de la mayoría de los países europeos, la menor intensidad de las políticas de austeridad ocasionada 
por la autorización comunitaria de retrasar de 2013 a 2016 la fecha límite para el cumplimiento del déficit público del 3\% del PIB o la brusca caída de la prima de riesgo provocadas por las declaraciones del señor Draghi de julio de 2012, puede explicar el final de la recesión económica en España a mediados de 2013. El mantenimiento de la evolución positiva del PIB intertrimestral a lo largo de 2014 y principios de 2015 se explicaría también por la existencia de otros factores exógenos a la economía española y que poco tienen que ver con la estrategia económica decidida por el gobierno español, contrariamente a lo defendido por su presidente y por el ministro de economía. Entre estos factores, habría que mencionar a fenómenos que se están produciendo a nivel internacional desde mediados de 2014, como la notable depreciación del euro, que encarece las importaciones y abarata las exportaciones de los países del euro y, por lo tanto, de España, y la caída del precio del petróleo, en un país como España en que la dependencia energética de las importaciones petrolíferas es tan significativa. Aparte claro del giro del Banco Central Europeo hacia una política monetaria más expansiva en los últimos meses con la compra de deuda, incluida la pública.

No parece, por lo tanto, que ni la política de austeridad ni las reformas laborales aprobadas a lo largo de la crisis económica hayan podido ser la causa del cambio de la situación económica. Y ello porque las consecuencias más directas e inmediatas de la austeridad significaron un sustancial retroceso de la demanda agregada por el descenso del gasto público y el aumento de los impuestos que esa política supuso. La política de austeridad fiscal ni mejoró la confianza de los mercados ni redujo la prima de riesgo. Ello se consiguió más tarde por factores que nada tienen que ver con esa política al depender, como se acaba de explicar, de factores y fenómenos totalmente ajenos a la economía española.

Tampoco la devaluación, reflejada en la disminución de los salarios reales (en más del 7\%) desde 2010 y en la reducción de los salarios monetarios desde 2012, lo que ha repercutido en una caída desde 2010 de los CLU monetarios y reales, parece que haya tenido fuerza suficiente para provocar el aumento de la producción y, en consecuencia, del empleo como han insistido los defensores de esa política. Y ello porque, aunque la reducción de los CLU puede propiciar que a las empresas individualmente consideradas les sea rentable, en principio, aumentar la producción, este aumento no tendrá lugar en realidad a nivel macroeconómico, del conjunto de las empresas, si el descenso de los salarios reales, y no digamos nada de los monetarios, provoca la contracción de la demanda agregada por la disminución de 
los ingresos de los trabajadores que ello traería consigo. Este es el fenómeno de la paradoja de la flexibilidad salarial destacado en Krugman (2012), aunque la mayoría de los economistas ortodoxos rehúyen de él, al predominar en sus análisis la dimensión salarial como coste de las empresas y marginar la dimensión salarial como ingreso de los trabajadores y, por consiguiente, determinante, en gran medida, de la demanda agregada. Hay que tener en cuenta que en España más del $80 \%$ de la población ocupada es asalariada y que en torno al $60 \%$ del PIB se explica por el consumo privado.

$\mathrm{Y}$ si es difícil encontrar motivos teóricos y empíricos para justificar que las reformas laborales sean favorables a la actividad económica parece que lo mismo ocurrirá en relación con el empleo y ello a pesar de algunas de las evaluaciones de la reforma laboral de 2012 realizadas por instituciones oficiales europeas $y$ españolas que aseveran que la reforma laboral ha favorecido la creación de empleo ${ }^{35} \mathrm{o}$ que ha amortiguado la destrucción del empleo que se hubiera producido en ausencia de la reforma laboral ${ }^{36}$, todo ello, como se ha señalado, proyectando la situación anterior a 2012 hacia períodos posteriores y comparando esas proyecciones con la situación que reflejan las estadísticas del mercado de trabajo, concretamente la EPA, en los mismos periodos.

La realidad es que, después del cambio de la política económica que se produce desde la primavera de 2010 y de las reformas laborales aprobadas desde entonces, la evolución del empleo no solo no mejora sino que empeora. Ya se ha señalado, que, en contra de los beneficiosos efectos sobre la actividad económica que proclaman los defensores de la política de austeridad, no parece que estos se hayan producido. Y, además, tampoco parece que las reformas laborales hayan corregido las consecuencias desfavorables sobre el empleo que la estrategia de consolidación y austeridad fiscal tiene sobre la actividad económica. Y ello porque es muy difícil que las reformas laborales por sí mismas favorezcan la creación de empleo, máxime en una situación de crisis económica como la que ha caracterizado a España desde inicios de 2008. Porque ante todo el empleo, la demanda de trabajo, es una demanda derivada de la producción y cuando la actividad económica

\footnotetext{
35 En la citada evaluación de OCDE (2014) se llega a concluir, entre otras afirmaciones, que en los primeros dieciocho meses que transcurren desde la aprobación de la reforma laboral de 2012 se crearon 25.000 empleos indefinidos al mes.

36 En Ministerio de Empleo y Seguridad Social (2013) se afirma que en el período que transcurre entre el segundo trimestre de 2012 y el primero de 2013 se destruyeron 225.000 empleos menos que los que se hubieran destruido si no se hubiese aprobado la reforma laboral de 2012 .
} 
tiene una evolución negativa, por muchas reformas laborales que se aprueben, es muy difícil que esa evolución se corrija. Y, todavía más, si se tiene en cuenta el tipo de medidas aprobadas, entre otras la mayor facilidad y el abaratamiento del despido que en situaciones de crisis profunda como la española tienden a prevalecer sobre otras medidas alternativas de flexibilidad interna como las mayores posibilidades de modificar las condiciones de trabajo.

Aunque es cierto que han podido coincidir dos respuestas distintas ante la crisis, el despido y la disminución de los salarios, ya hemos indicado que, pese a las explicaciones de los economistas ortodoxos, no parece que sea ineludible que la devaluación salarial vaya unida irremediablemente a una mejora de la actividad económica y el empleo porque el efecto que tiene sobre la disminución de los ingresos de los trabajadores y la demanda efectiva puede contrarrestar el efecto sobre la reducción de los costes laborales unitarios de las empresas. Y esto es lo que parece que ha ocurrido realmente con el empleo. En efecto, desde el inicio de la crisis económica y hasta finales de $2014^{37}$, y pese a que desde mediados de 2013 se ha producido una ligera creación de empleo en coherencia con el final de la recesión económica, según las estimaciones de la Encuesta de Población Activa (EPA), el empleo neto ha disminuido en casi 3,2 millones, más de un $15 \%$ en términos relativos, lo que explica un enorme crecimiento del paro, de más de 3,6 millones de personas en el mismo período de tiempo en el que la cifra más que se triplica, hasta situarse en el cuarto trimestre de 2014 el número de personas paradas en más de cinco millones y medio y la tasa de paro en el 23,7\%.

Pero es que, además, el descenso del empleo que se había atenuado notablemente desde la primavera de 2009 como consecuencia de la política de incentivos fiscales que se inició entonces, vuelve a acentuarse considerablemente a partir de finales de 2010, como reflejo de endurecimiento de la política económica en la primavera de ese año. Y a partir de la aprobación de la reforma laboral de 2012 la caída del empleo, en vez de aminorarse, se intensifica entre el segundo semestre de 2012 y el primero de 2013. No parece, por lo tanto, que se confirme la mejora derivada de la reforma laboral de la evolución del empleo ni tan siquiera la menor destrucción de empleo que se deduce de las evaluaciones de la reforma laboral de 2012 realizadas por el gobierno o

$37 \mathrm{El}$ período considerado es el que transcurre entre el tercer trimestre de 2007 y el cuarto de 2014, puesto que, aunque en el texto se considera que la crisis en España comienza a principios de 2008, el empleo ya disminuía desde el cuarto trimestre de 2007. 
la OCDE. Que la destrucción de empleo hubiera sido mayor sin la aprobación de la reforma laboral puede ser o puede no ser, quien sabe, pero no parece que sea suficientemente consistente con los datos disponibles, aparte de que los procedimientos utilizados para alcanzar esas conclusiones no parecen tampoco demasiado rigurosos. En cualquier caso, la reforma laboral no ha sido capaz de corregir la evolución negativa que venía produciéndose en el empleo. Y de todas formas tampoco parece muy coherente que se intente separar los efectos de la política de austeridad de los de las reformas laborales pues ambas forman parte de una estrategia común y global y tienen similares justificaciones desde la perspectiva de la economía ortodoxa.

Aparte claro de que las consecuencias perjudiciales y el elevado coste social de esas políticas se mantienen todavía después de dos años de haber finalizado la recesión económica, como se constata con el elevado número de personas en paro, que supera los cinco millones y representa casi la cuarta parte de las personas activas, la difícilmente soportable importancia del paro de larga duración, que asciende a más de los dos tercios del paro total, y el considerable crecimiento de la pobreza y la desigualdad que ha acompañado a las políticas instrumentadas en los últimos años.

\section{3. ¿Y las fluctuaciones del empleo se han reducido?}

Por otra parte, las reformas laborales aprobadas en los últimos años, no solo la de 2012, tampoco parece que hayan servido para reducir la fuerte inestabilidad de empleo, su comportamiento muy fluctuante, más intensamente procíclico que el comportamiento de otros países, de modo que cuando la economía crece el avance del empleo es muy acusado, mayor que en casi todos los países de la zona del euro, y cuando la economía se encuentra en una situación de crisis o recesión la destrucción de empleo es muy intensa, también mayor que en prácticamente todos los países de la zona del euro. Esto es lo que se deduce de la elasticidad empleo-producción (incremento relativo del empleo/incremento relativo del PIB), que en España es muy superior a la unidad, cuando en la mayoría de los países del euro es muy inferior a la unidad, algo que no se ha alterado ni mucho menos con la entrada en vigor de las últimas reformas laborales ${ }^{38}$.

\footnotetext{
38 Para el período 2001-2014, en el que coexisten fases expansivas y de crisis económica, la elasticidad empleo-producción ascendió a 2,2, más de 4 veces $(4,4)$ la de la media de la zona del euro, 0,5 .
} 
Esta muy elevada sensibilidad del empleo en relación con el PIB en España incide también en el comportamiento de la productividad por ocupado de la economía española. En efecto, cuando en la gran mayoría de los países europeos en los que el empleo es más estable y menos fluctuante la productividad por ocupado ha tendido a ser decreciente o a tener un comportamiento pocíclico, al aumentar más en las expansiones que en las crisis y recesiones, en España, por el contrario, ha tenido un comportamiento claramente anticíclico, al crecer más en las crisis o recesiones que en las recuperaciones y expansiones. Eso es la que se deduce claramente ${ }^{39}$ de los datos disponibles para la economía española, en los que el crecimiento de la productividad por ocupado en los dos años anteriores a la crisis, $2006 \mathrm{y}$ 2007, fue solo el $0,1 \%$ y el $0,5 \%$, respectivamente, en 2008 en el año de inicio de la crisis repunta hasta el 0,9\% y, posteriormente, incluyendo, el primer semestre de 2013, todavía en situación de recesión económica, los avances de la productividad por ocupado se sitúan en torno al $2 \%$ o, incluso, por encima de esa cifra, más de cuatro veces las que se producían antes de la crisis.

Y este comportamiento de la productividad por ocupado, como se ha señalado, tiene mucho que ver con las grandes oscilaciones procíclicas del empleo en España, es decir, con el muy elevado valor de la elasticidad empleo-producción, que, a su vez, está relacionado con que históricamente los ajustes de las empresas a los cambios de la situación económica se han hecho básicamente vía el empleo, en vez, de utilizar preferentemente otras vías, como es el caso de Alemania a través de la jornada laboral.

Y la explicación de este comportamiento de las empresas como se expone en Pérez Infante, J.I (2015b) puede tener varias causas. Por un lado, el modelo productivo en el que tienen una importancia relativa mayor que en otros países desarrollados las actividades relacionadas con la construcción y el turismo, muy estacionales, y las de nivel tecnológico bajo-medio, el predominio de las pequeñas y medianas empresas, ya que las de menos de seis trabajadores suponen el $65 \%$ del total y las de menos de diez trabajadores el 85\%, y la acusada importancia que en muchos sectores, no solo en los que su actividad económica es principalmente estacional, tienen los puestos de trabajo inestables con una continuidad muy incierta y muy condicionada a las

\footnotetext{
39 PIB real o en volumen / empleo equivalente a tiempo completo. La única estadística que permite calcular la productividad por ocupado es la Contabilidad Nacional de España (CNE). Para calcularla se utiliza el empleo equivalente a tiempo completo que tiene en cuenta la jornada trabajada.
} 
circunstancias del muy corto plazo. Todas estas características, muy relacionadas con un bajo nivel de formación y de cualificación, y que en gran medida desincentiva las actuaciones de formación profesional en la misma empresa, además de explicar niveles de productividad muy reducidos, también justifican que el empleo sea muy inestable y fluctuante, muy dependiente de las circunstancias económicas de las empresas y de la economía en general.

Pero, además, este comportamiento históricamente muy fluctuante del empleo, se ha visto también favorecido por la facilidad que las empresas españolas tienen para el empleo temporal, y ello no porque la regulación de la contratación temporal sea muy flexible, más que en otros países de nuestro entorno, como se confirma con las comparaciones internacionales realizadas en OCDE (2014) entre distintos países del grado de protección del empleo temporal. Y esto es así porque, salvo para el caso de las personas discapacitadas, la contratación temporal en España es causal, solo puede celebrarse cuando exista una causa que la justifica, por ejemplo, que la actividad tenga una duración determinada. Por lo tanto, parece que sea, más bien que la regulación de la contratación temporal, la casi absoluta falta de control de este tipo de contratación lo que ha provocado que muchas empresas hagan un uso abusivo, irregular y hasta fraudulento de la contratación temporal y lo que explicaría la facilidad en la práctica de las empresas españolas para la contratación temporal. A ello debe añadirse la cultura de temporalidad de muchas empresas, que se genera con la flexibilización que se produjo en la reforma laboral de 1984, y que ha persistido a pesar de que muchas de las reformas laborales posteriores han pretendido, aunque, con escaso éxito, limitarla y mitigarla ${ }^{40}$.

$\mathrm{Y}$ este comportamiento tiene una gran relevancia, puesto que la variación de la productividad por ocupado equivale a lo que podemos denominar umbral de creación de empleo, lo que tiene que aumentar el PIB para que el conjunto de la economía genere (cree) empleo neto. Y que la evolución de la productividad sea anticíclica significa que en situaciones de crisis el citado umbral, lo que tiene que crecer el PIB para que comience a aumentar el empleo, será superior al correspondiente a las situaciones de expansión económica, y, por lo tanto, la capacidad generadora de empleo de la economía será muy inferior en las situaciones de crisis que en las de recuperación económica o en las expansivas.

40 Una de las únicas reformas laborales que no establece ninguna limitación ni condicionamiento a la contratación temporal ha sido, precisamente, la de 2012. 


\section{4. ¿Y cómo ha evolucionado el umbral de creación de empleo, la capacidad generadora de empleo?}

La pregunta que conviene hacerse es, ¿qué ha ocurrido a partir de la reforma laboral de 2012 con la capacidad generadora de empleo de la economía española?, ya que el gobierno ha argumentado reiteradamente como prueba del éxito de la reforma laboral que esta ha provocado el aumento de la capacidad generadora de empleo de la economía española, es decir, que ha descendido el umbral de creación de empleo, como consecuencia de la mayor flexibilidad interna (mayor posibilidad de modificar las condiciones de trabajo) y salarial (devaluación) que ha supuesto esa reforma laboral para las empresas españolas, lo que habría hecho según el gobierno menos necesario el despido.

En realidad el umbral de creación del empleo y, por consiguiente, el crecimiento de la productividad por ocupado en 2012, el $2,4 \%$, y en el primer semestre de 2013, el 2,2\%, fue muy elevado, superior al que se produjo en 2011, el 1,9\%. Y este crecimiento de la productividad por ocupado solo empieza a disminuir en términos interanuales con el final de la recesión económica en el segundo semestre de 2013, con el 1,9\%, y continúa con esa tendencia decreciente en 2014, con el 0,3\%. Es más en el primer semestre de 2015 con un avance interanual del PIB real del 2,9\% la productividad por ocupado aumentaba a un ritmo de solo el $0,1 \%$, el mismo que el correspondiente a 2006, antes del inicio de la crisis.

Parece, por consiguiente, que la evolución de la productividad por ocupado sigue teniendo un comportamiento anticíclico y que esta es la razón principal de descenso del umbral de creación del empleo a partir del final del período de recesión económica en el segundo trimestre de 2013, con niveles inferiores a la unidad, incluso cercanos a cero, como ocurría en los años anteriores al inicio de la crisis económica en 2008, más que por los efectos de la citada reforma laboral como con insistencia argumenta el gobierno. Y ello porque ninguna de las causas explicativas de ese comportamiento anticíclico, como el modelo productivo, la falta de control de la contratación temporal y la cultura de temporalidad de las empresas, han sufrido alteración alguna como consecuencia de esa reforma laboral. Es más, en 2012 no se ha introducido modificación normativa alguna de limitación de la contratación temporal, en cambio, se ha facilitado y abaratado el despido, lo que en situaciones de crisis económica ha podido contrarrestar las mayores posibilidades de flexibilidad interna que también se introdujeron en ese año, como se deduce de la continuación 
del fuerte ajuste de empleo de las empresas que se ha mantenido hasta el final de la recesión, tanto por la extinción de contratos temporales como por el despido de trabajadores indefinidos ${ }^{41}$.

Aparte de que, si hubiera funcionado eficazmente las mayores posibilidades de flexibilidad interna y de los salarios, y se hubieran frenado los ajustes de empleo, las empresas habrían mantenido durante el último año y medio de recesión económica trabajadores sin utilizar plenamente en una cuantía mayor y entonces las necesidades de contratación en el inicio de la recuperación económica hubiesen sido menores que las que realmente se han producido. Y ese mayor atesoramiento de mano de obra de las empresas hubiera provocado un menor ritmo de aumento de la productividad por ocupado en la fase final de la recesión económica y un mayor crecimiento de esa magnitud durante el comienzo de la recuperación económica por la mayor utilización de la mano de obra no utilizada plenamente en los meses anteriores. Y lo que ha ocurrido ha sido, como se ha señalado, precisamente lo contrario ${ }^{42}$.

\section{5. ¿Y la competitividad de la economía española ha mejorados sustancialmente como consecuencia de las reformas laborales?}

$\mathrm{Y}$, por último, cabe preguntarse si las reformas laborales, y, en particular, la de 2012 han tenido otros efectos positivos, como puede ser la mejora de la competitividad de la economía española, relacionada por los economistas ortodoxos y los organismos económicos con la devaluación salarial, es decir, con la disminución de los costes laborales unitarios de las empresas, que se ha producido en los últimos años y de lo que no es ajena la pérdida o debilitamiento de la capacidad negociadora de los trabajadores, que, aunque originada, en un principio, por la desmesurada destrucción de empleo, se agudiza por los efectos desequilibradores de esa reforma laboral, y, especialmente, por las modificaciones que introduce en la negociación colectiva.

Pero, es que, como he señalado en varias ocasiones ${ }^{43}$, la mejora de la competitividad de una economía, al contrario de lo que se suele sostener no es algo que inevitable e ineludiblemente vaya unida a la

41 Un análisis del flujo de salida del empleo por despidos y finalización de la contratación temporal puede verse en Pérez Infante (2015a).

42 Un análisis más detallado puede encontrarse en Pérez Infante (2015a). En cuanto al análisis de la precariedad del empleo no resuelta por la reforma de 2012, pueden verse los artículos de Cebrián López y Moreno Raymundo (2011) y (2012) y Cebrián López (2015).

${ }^{43}$ Pérez Infante (2013b), (2013c), (2015a) y (2015b). 
reducción de los costes laborales unitarios por varias razones, entre las que pueden señalarse tres. La primera, que lo verdaderamente significativo para el análisis de la competitividad de una economía es el coste total unitario de producción (coste total por unidad de producción) y no solo el coste laboral unitario, porque, por ejemplo, el descenso de este puede verse contrarrestado por el aumento de los restantes costes unitarios, como los derivados de la energía, de los impuestos o de la financiación de las empresas. La segunda, porque puede ocurrir que el descenso de los costes laborales unitarios no se traslade ni directa ni en la misma cuantía a disminuciones de los precios ${ }^{44}$ si las empresas aprovechan que tienen algún grado de control monopolístico de sus mercados para, en vez de bajar sus precios, elevar su tasa o margen de ganancia. Y, la tercera, porque, aunque la devaluación salarial se hubiera trasladado a los precios interiores, la evolución del tipo de cambio de la moneda (el euro en este caso) puede compensar, e incluso superar, el descenso de los precios nacionales respecto de los extranjeros, que es lo que puede ocurrir si la moneda se aprecia con suficiente intensidad, ya que ello provoca un abaratamiento de las importaciones y un encarecimiento de las exportaciones del país.

$\mathrm{Y}$ algunas de estas cosas o todas puede que hayan ocurrido en España desde 2010, puesto que los precios reales relativos o tipo de cambio efectivo real de la economía española ${ }^{45}$, el indicador que mide la posición y la evolución de la competitividad de una economía, ha aumentado y no disminuido, si se consideran los precios de producción interior, el llamado deflactor del PIB, y si se considera su variación en ese período en relación con tres grupos de países, zona del euro, UE o el conjunto de los países desarrollados (OCDE). Es decir, el descenso de los costes laborales unitarios no ha mejorado la competitividad de la economía española respecto de esos tres grupos de países por alguna combinación de las tres situaciones señaladas anteriormente: aumento de otros costes de producción que contrarresta el descenso de los laborales, incremento del margen de ganancia de las empresas o apreciación del euro ${ }^{46}$.

Solo en 2014 se produce una clara mejoría de la competitividad de la economía española y ello no necesariamente por razones relacionadas con la devaluación salarial o, por lo menos, no únicamente

\footnotetext{
${ }^{44}$ Hay que tener en cuenta que lo verdaderamente relevante no es solo la evolución de los precios interiores o nacionales sino su relación con los exteriores, con los precios de otros países $\left(\mathrm{P}_{\mathrm{N}} / \mathrm{P}_{\mathrm{E}}\right)$, su abaratamiento o encarecimiento relativo.

45 Tipo de cambio efectivo real $=\mathrm{P}_{\mathrm{N}} / \mathrm{P}_{\mathrm{E}} \mathrm{x}$ Tipo de cambio nominal.

46 Véase Pérez Infante (2015b).
} 
por esas razones. En efecto, en la mejora de la competitividad de la economía española que se produce en 2014 parece estar influyendo otros factores diferentes a la devaluación salarial. El más importante, probablemente, sea la notable depreciación del euro que se produce en ese año y que rompe la tendencia dominante a la apreciación que se había venido produciendo desde la creación del euro, que encarece las importaciones y abarata las exportaciones españolas respecto de los países no incluidos en la zona del euro. Y también influye en la mejora de la competitividad de la economía española de ese año la intensa caída del precio del petróleo por la repercusión que en los precios relativos españoles tiene la mayor dependencia de España en comparación con otros países de nuestro entorno respecto de las importaciones de este input, imprescindible en la producción de una generalidad de bienes y servicios. Y, además, en el abaratamiento relativo de los precios interiores respecto de los exteriores de 2014 más que la devaluación salarial puede estar influyendo el intenso debilitamiento acumulado desde 2008 de la demanda agregada, más acusado que en otros países europeos, lo que ha podido incidir en que la caída de los precios en España haya sido más acentuada que la que se ha producido en otros países desarrollados. Aparte de que esa mejora de la competitividad tan generalizada en 2014 no se está produciendo en los meses transcurridos de 2015, puesto, que con datos del primer semestre, solo se está produciendo con relación a los países desarrollados que no forman parte de la Unión Europea, mientras que en relación con la zona del euro y el conjunto de la UE está empeorando.

\section{Conclusiones}

Las reformas laborales aprobadas desde 2010 forman parte, junto a la austeridad fiscal, de una estrategia de política económica aprobada a partir de la primavera de ese año por los distintos gobiernos españoles ante la presión de las instituciones europeas y que se intensifica notablemente desde el verano de 2011, como resultante de la carta al presidente del gobierno señor Zapatero de los gobernadores del Banco Central Europeo y del Banco de España. El nuevo gobierno del PP constituido en la Navidad de 2012 todavía intensifica más esa estrategia.

De las distintas reformas laborales aprobadas desde 2010 destaca, pese a los aspectos comunes a todas ellas, la aprobada en febrero de 2012 por Real Decreto-ley y ratificada en julio del mismo año 
al transformarlo, con alguna modificación, en Ley. Y destaca por su mayor radicalidad en casi todos los aspectos de la normativa laboral y, sobre todo, por la considerable flexibilidad laboral que introduce, y que provoca un notorio desequilibrio en el marco de las relaciones laborales, al potenciar y favorecer el principio de libertad de empresa, al mismo tiempo que refuerza el poder empresarial, en detrimento muchas veces de los derechos de los trabajadores y de su capacidad negociadora, lo que propicia tanto el aumento de la desigualdad como de las situaciones de pobreza de muchos trabajadores.

Precisamente frutó de ese desequilibrio de las relaciones laborales, y a pesar de que no figure expresamente entre sus objetivos principales, el mayor impacto de esas reformas, especialmente de la de 2012, es la devaluación salarial, que, sobre todo, afecta a los trabajadores con menores salarios, de forma que a la pérdida del poder adquisitivo del conjunto de los salarios, que ya venía produciéndose desde 2010, se añade la reducción del salario monetario medio.

Pero, aparte de la devaluación salarial, que se muestra como el impacto económico más directo para los trabajadores, no solo privados, sino también públicos, de toda esa estrategia de austeridad y de reformas laborales, en el artículo nos hemos interrogados sobre la existencia de otros efectos sobre el conjunto de la economía, ya que tanto el gobierno como los defensores de esa clase de política mantenían y todavía mantienen en gran medida que de su puesta en práctica se derivaría la mejora de la confianza de los mercados en la economía española y que, en concreto, la rebaja de los costes laborales unitarios que acompañaría a la devaluación salarial (de devaluación interna hablan) estimularía la actividad económica y el empleo, además de la mejora de la competitividad de la economía española que esa devaluación acarrearía.

Pues bien, como se argumenta en el artículo, no parece que la realidad confirme esos pronósticos tan propicios y beneficiosos para la economía española. Y no solo por la entrada en un nueva recesión económica a principios de 2011 que se acentúa a lo largo de 2012 y dura hasta el segundo trimestre de 2013 sino porque también el inicio de la recuperación que se produce a partir de ese trimestre se explica por razones totalmente ajenas a las políticas de austeridad y de devaluación salarial, de naturaleza totalmente exógena a la economía española y a la puesta en práctica de esas políticas.

$\mathrm{Y}$ es que la ligera mejora de la actividad económica y el empleo que se produce a partir del verano de 2013 responden a una serie de fenómenos que no tienen ninguna relación ni con la puesta en marcha de la austeridad ni con la aprobación de las reformas laborales, sino con 
factores ajenos a la economía y a la política económica españolas. Entre estos factores, cabría resaltar la mejora de la economía de otras importantes economías, la decisión de la Unión Europea de flexibilizar temporalmente el cumplimiento del déficit del $3 \%$ del PIB, lo que permitió una cierta relajación de la política de austeridad, la política monetaria más expansiva del Banco Central Europeo, la depreciación del euro y la caída del precio del petróleo que beneficia con especial intensidad a la economía española por la elevadísima dependencia de las importaciones de ese producto.

Pero, además, las reformas laborales no han repercutido favorablemente en aspectos relacionados con el mercado de trabajo y las relaciones laborales, sino todo lo contrario, ya que, por un lado, no han reducido en absoluto la volatilidad $\mathrm{y}$ fuertes fluctuaciones del empleo, por la permanencia, pese a las mayores posibilidades de modificación de las condiciones de trabajo, de la vía principal de ajuste del empleo de las empresas a los cambios de las condiciones de trabajo.

Como consecuencia de las fuertes fluctuaciones del empleo, que se manifiestan en elasticidades empleo-producción, muy elevadas, muy superiores a las de la gran mayoría de los países desarrollados, el umbral de creación del empleo, lo que tiene que crecer el PIB para que la economía cree empleo, que fue muy alta durante los períodos de recesión económica, ha caído notablemente al finalizar esa recesión, lo que ha supuesto una mejora de la capacidad generadora de empleo de la economía española, que, en contra de lo que mantiene el gobierno, no se ha producido por los cambios de la reforma laboral de 2012 sino por la tendencia histórica de la economía española desde principios de la década de los ochenta del pasado siglo, muy relacionada con el ciclo económico, a que en las recuperaciones el citado umbral de creación de empleo es muy inferior al correspondiente a las fases de crisis y recesión económica.

Y ello ha ocurrido así porque ninguno de los fenómenos explicativos de ese comportamiento de la productividad por ocupado se han visto en absoluto alterados por la estrategia de política económica de política de austeridad y de reformas laborales obsesionada la primera con la reducción del déficit público y la deuda pública, que ha seguido creciendo a pesar de todo y las segundas con la devaluación salarial y que en ningún momento ha afectado al modelo productivo ni a la importancia de la temporalidad y la precarización del empleo, que incluso se ha acentuado desde el inicio de la recuperación económica.

$\mathrm{Y}$, por último, tampoco la reducción del coste laboral unitario derivada de la devaluación salarial ha provocado una mejora clara de la competitividad de la economía española, porque esa mejora depende 
también de otros factores diferentes a los salariales, que han podido incidir en el sentido contrario, como, la tendencia del euro a apreciarse respecto a otras monedas, especialmente respecto del dólar, la compensación, al menos parcial que se ha podido producir en los costes unitarios totales de producción al aumentar otros costes diferentes a los laborales, como los energéticos y los impositivos, y el aumento del margen empresarial que parece que se ha producido en ciertos mercados muy estratégicos con control monopolístico de unas pocas empresas. Fruto de todo ello ha sido que el retroceso del coste laboral no se ha trasladado en la misma medida a los precios o que, finalmente, los productos españoles no se hayan abaratado relativamente con otros países.

Sólo en 2014 se ha producido una cierta mejora de la competitividad de la economía española y ello por razones diferentes a las de la disminución de los costes laborales unitarios, ya que esa mejora ha sido consecuencia tanto de la importante depreciación del euro que se ha producido en ese año como por la incidencia en el abaratamiento relativo de la producción interior española, debido a factores tales como la caída de los precios del petróleo que repercute en mayor medida en economías como la española muy dependiente de las importaciones de petróleo y el retroceso acumulado de la demanda interna, muy superior al que se ha producido en otras muchas economías.

\section{Bibliografía}

Banco de España (2013): "La reforma laboral de 2012. Un primer análisis de algunos de sus efectos sobre el mercado de trabajo". Boletín Económico, septiembre.

Blyht, M (2013): "Austeridad. Historia de una idea peligrosa". Crítica. Barcelona.

Casas Baamonde, M.E. Rodríguez-Piñero Beavo-Ferrer, M. y Valdés Dal-Rê (2012): "La nueva reforma laboral de 2012". Relaciones Laborales, 5 de 2012.

Cebrián López, I (2015): "La reforma laboral de 2012 y la flexiseguridad. Aspectos económicos". Publicado en Pérez Infante, J.I. y Ruesga Benito, S.M. (2015). 
Cebián López, I. y Moreno Raymundo, G (2011): "La estabilidad laboral y los programas de fomento de la contratación indefinida". Hacienda Pública Española 198 (3/3011).

Cebrián López, I. y Moreno Raymundo, G. (2012): "La estabilidad de los nuevos contratos indefinidos durante la crisis económica". Estudios de Economía Aplicada vol. 30, I 2012.

Ekaizer, E. (2012): "Indecentes. Crónica de un atraco perfecto". Espasa libros. Madrid.

Gómez Sánchez, V. (2009): "La reforma laboral en España". Biblioteca Nueva. Fundación Ortega y Gasset. Madrid.

Guamán Hernández, A. e Illueca Ballester, H. (2012): "El huracán neoliberal. Una reforma laboral contra el trabajo". Sequitur. Madrid.

Krugman, P. (2012): "Acabad con esta crisis!". Crítica. Barcelona.

Malo, M.A. (2012a): "Una primera aproximación a la reforma laboral de 2012". Cuadernos de Información Económica 226.

Malo, M.A. (2012b): "La reforma laboral de 2012. Cambios e incertidumbres". Papeles de Economía 133.

Ministerio de Empleo y Seguridad Social (2013): "Informe de Evaluación del impacto de la reforma laboral de 2012". Mimeo.

OCDE (1997): "Los resultados económicos y la estructura de la negociación colectiva". En Perspectivas del empleo, 1997. Traducción del Ministerio de Trabajo y Seguridad Social. Madrid.

OCDE (2004): "La fijación de los salarios: aspectos institucionales y resultados". En Perspectivas del empleo, 2004. Traducción del Ministerio de Trabajo e Inmigración. Madrid.

OCDE (2006): "Medidas generales para mejorar las oportunidades de empleo para todos". En Perspectivas de empleo, 2006. Traducción del Ministerio de Trabajo e Inmigración. Madrid. 
OCDE (2014):"La reforma laboral se 2012 en España. Evaluación preliminar". Informes OCDE. Traducción del Ministerio de Empleo y Seguridad Social. Madrid.

Pérez Infante, J.I. (2013a): "El análisis neoliberal del mercado de trabajo". Artículo publicado en la página web de Economistas Frente a la Crisis (www.economistasfrentealacrisis.com).

Pérez Infante, J.I. (2013b): "Crisis, reformas laborales y devaluación salarial". Relaciones Laborales. Revista Crítica de Teoría y Práctica número. 10, año 29, octubre de 2013.

Pérez Infante, J.I. (2013c): "Las reformas de la negociación colectiva desde una perspectiva económica". Temas Laborales. Revista Andaluza de Trabajo y Bienestar Social, 120/2013.

Pérez Infante, J.I. (2013d): "Crisis económica, empleo y salarios". Documentación Social. Revista de Estudios Sociales y de Sociología Aplicada, 169.

Pérez Infante, J.I. (2015a): "Las reformas laborales en la crisis económica: su impacto económico". EKONOMIAZ 87, Primer semestre de 2015 .

Pérez Infante, J.I. (2015b): "Las reformas de la negociación colectiva y la devaluación salarial". Ponencia presentada en las XI Jornadas de Economía Laboral, organizadas por la Asociación Española de Economía del Trabajo y celebradas en la Universidad Autónoma de Barcelona en julio de 2015. Incluida en aeet-jel.es (secciones paralelas II sesión 10 reformas laborales).

Pérez Infante, J.I. y Ruesga Benito, S. M.(2015) (editores): "Reformas laborales en la Gran Recesión". Tirant lo Blanc. Valencia (en imprenta).

Toharia, L. y Malo, M.A. (2009): "¿Qué se puede esperar de las reformas del mercado de trabajo?". Circunstancias 20. Revista electrónica de la Fundación Ortega y Gasset (www.ortegaygasset.es), publicado en Gómez Sánchez, V. (2009). 